\title{
PENERAPAN MODEL JOINT ECONOMIC LOT SIZE PADA PT. MPX ANTARA PEMANUFAKTUR DAN MULTI PEMBELI DENGAN PERMINTAAN PROBABILISTIK
}

\author{
Deny Santining Tyas ${ }^{1}$, Moch. Anshori ${ }^{2}$ \\ e-mail : denysantiningtyas@gmail.com, anshoorii@yahoo.com \\ Fakultas Teknik, Jurusan Teknik Industri, Universitas Maarif Hasyim Latif \\ Jl. Ngelom Megare, Taman Sidoarjo 61257
}

\begin{abstract}
ABSTRAK
PT. MPX adalah perusahaan pengelola coklat yang memiliki permasalahan mengenai pengelolaan persediaan dengan distibutornya, sehingga menyebabkan tidak stabilnya permintaan dari kedua pembeli, serta tidak ada waktu pengiriman yang optimal untuk keduanya. Pada kondisi nyata pihak pembeli dan pemanufaktur menetapkan ukuran lot optimalnya masing-masing, sehingga penulis melakukan penelitian untuk mencari lot pengiriman dan biaya optimal untuk semua level. Penelitian ini menerapkan metode JELS (Joint Economic Lot Size) antara pemanufaktur tunggal dan multi pembeli dengan permintaan probabilistik. Hasil dari analisa ini membuktikan bahwa dengan menerapkan metode JELS (Joint Economic Lot Size) pada pemanufaktur tunggal dan multi pembeli menghasilkan total biaya yang lebih kecil dibandingkan tanpa menggunakan metode JELS (Joint Economic Lot Size) serta didapatkan waktu pemesanan yang optimal bagi kedua pembeli.
\end{abstract}

Keyword : permintaan probabilistik, lot pengiriman rantai pasok, joint economic lot size.

\section{PENDAHULUAN}

Semakin berkembangnya zaman maka persaingan bisnis disegala bidang usaha juga akan meningkat. Peningkatan persaingan bisnis tersebut menjadi salah satu pemicu munculnya manajemen rantai pasok. Manajemen rantai pasok merupakan pendekatan untuk pengelolaan inventori dan distribusi secara terintegrasi antara pemasok, produsen, disributor dan pengecer.

PT. MPX memiliki permasalahan mengenai pengelolaan persediaan dengan distributornya. Permasalahan yang dihadapi dalam aktivitas normal perusahaan adalah tidak stabilnya permintaan dari kedua pembelinya, serta tidak ada waktu pengiriman yang optimal untuk keduanya. PT. MPX menggunakan pendekatan sistem Economic Production Quantity untuk mengelola persediaannya saat ini, sedangkan pada pembelinya menggunakan pendekatan metode periodik untuk mengelola persediaannya.

Kurangnya integrasi yang baik dalam rantai pasok dapat menyebabkan kerugian bagi satu atau beberapa pihak yang akan melemahkan daya saing rantai pasok. Oleh sebab itu, penulis tergerak untuk membandingkan antara tanpa adanya penerapan model JELS (Joint Economic Lot Size) dengan penerapan model JELS (Joint Economic Lot Size) pada pemegang rantai pasok. Hubungan pembeli dan pemasok, JELS dapat ditemukan pada permasalahan integrasi pemasok-pembeli untuk menentukan ukuran lot pemesanan dari pembeli ke pemasok dan ukuran batch produksi pemasok yang meminimumkan total biaya gabungan dari kedua pihak, serta integrasi pengadaan-produksi untuk menentukan ukuran batch produksi dan ukuran lot pemesanan bahan baku untuk meminimumkan total biaya gabungan dari kedua aktivitas. Antara perusahaan, pembeli dan pemasoknya tidak terdapat kerjasama, dimana keputusan dibuat atas dasar kepentingannya masing-masing. Kondisi tersebut dapat dikarakteristikan dengan orientasi jangka pendek, negoisasi yang hanya berdasarkan harga, banyak pemasok, dan minimnya pemakaian informasi secara bersama. Semakin banyak perusahaan yang melakukan berbagai jenis koordinasi dan aliansi mengarah ke suatu bentuk kerjasama (partnership). Partnership menekankan pada pentingnya komitmen jangka panjang antara pembeli dan pemasok dimana kerjasama dibentuk atas dasar kepercayaan dan komitmen bersama. Hubungan antara pembeli dan pemasok yang lebih dekat biasanya dicirikan dengan pemakaian informasi secara bersama-sama dan saling bertukar ide. Partnersip juga dapat mengurangi halangan antara pembeli dan pemasok sehingga dapat diarahkan untuk meningkatkan aliran informasi, mengurangi ketidakpastian, dan meningkatkan profit. Integrasi pembeli-pemasok dimodelkan secara kuantitatif oleh beberapa peneliti dimulai 
dari setting permasalahan yang relatif sederhana. Pengendalian inventori yang menganjurkan pentingnya membuat keputusan bersama antara pembeli dan pemasok dalam menentukan pemesanan (Goyal 1977).

\section{METODE PENELITIAN}

Menurut (Prawirosentono 2001) Perencanaan dan Pengendalian bahan baku adalah suatu kegiatan memperkirakan kebutuhan persediaan bahan baku baik secara kualitatif maupun kuantitatif agar perusahaan dapat beroperasi seperti yang direncanakan. Untuk menentukan pengendalian persediaan bahan baku yang efektif maka diperlukan tujuan perencanaan yang efektif pula.

Penelitian ini berkaitan dengan pengelolaan persediaan maka peneliti membandingkan antara penerapan model JELS dengan tanpa adanya penerapan JELS. Menurut (Anshori, Pujawan, and Wiratno 2017) mengemukakan bahwa dalam suatu rantai pasok terdiri dari 3 stage yaitu pengadaan (procurement), produksi (production), dan distribusi (distribution) dimana untuk setiap stage mungkin terdiri dari beberapa fasilitas yang memiliki lokasi berbeda. Koordinasi dalam rantai pasok dibedakan menjadi 3 kategori koordinasi operasional yaitu:

1. Koordinasi pembeli-pemasok (buyervendor coordination)

2. Koordinasi produksi-distribusi (production-distribution coordination)

3. Koordinasi inventori-distribusi (inventorydistribution coordination).

Hubungan pembeli dan pemasok, JELS dapat ditemukan pada permasalahan integrasi pemasok-pembeli untuk menentukan ukuran lot pemesanan dari pembeli ke pemasok dan ukuran batch produksi pemasok yang meminimumkan total biaya gabungan dari kedua pihak, serta integrasi pengadaanproduksi untuk menentukan ukuran batch produksi dan ukuran lot pemesanan bahan baku untuk meminimumkan total biaya gabungan dari kedua aktivitas. Siklus pemesanan yang optimal pada masing-masing pembeli mengikuti model EOQ, dimana:

$$
T_{j}^{*}=\sqrt{\frac{2 A_{b, j}}{h_{b, j} \mu_{j}}}
$$

a. Siklus pemesanan optimal $\left(\mathrm{T}^{*}\right)$ dapat dirumuskan sebagai berikut :

$$
T^{*}=\sqrt{\frac{2 \sum_{j=1}^{n}\left(\lambda A_{b, j}+A_{v}+\sum_{i=1}^{k} a_{v, i}\right)}{\lambda\left(\sum_{j=1}^{n} \mu_{j} h_{b, j}+\left(h_{v}+\sum_{i=1}^{k} h_{v i} u_{i}\right)(\lambda-1)\left(\sum_{j=1}^{n} \mu_{j}\right)\right)}}
$$

\section{HASIL DAN PEMBAHASAN}

Pengumpulan data permintaan selama 2 tahun (24 bulan). Terlihat pada tabel 1 .

Tabel. 1. Data Permintaan

\begin{tabular}{|c|c|c|c|}
\hline \multicolumn{2}{|c|}{ Permintaan } & \multirow[b]{2}{*}{ Surabaya } & \multirow{2}{*}{ Total } \\
\hline Bulan & Solo & & \\
\hline Jan-15 & 393 & 2452 & 2845 \\
\hline Feb-15 & 500 & 2950 & 3450 \\
\hline Mar-15 & 0 & 3000 & 3000 \\
\hline Apr-15 & 350 & 3200 & 3550 \\
\hline Mei-15 & 300 & 1600 & 1900 \\
\hline Jun-15 & 300 & 2379 & 2679 \\
\hline Jul-15 & 579 & 2061 & 2640 \\
\hline Agust-15 & 0 & 2743 & 2743 \\
\hline Sep-15 & 200 & 3553 & 3753 \\
\hline Okt-15 & 450 & 3450 & 3900 \\
\hline Nop-15 & 550 & 1700 & 2250 \\
\hline Des-15 & 100 & 828 & 928 \\
\hline Jan-16 & 700 & 2807 & 3507 \\
\hline Feb-16 & 200 & 1869 & 2069 \\
\hline Mar-16 & 565 & 3600 & 4165 \\
\hline Apr-16 & 350 & 3654 & 4004 \\
\hline Mei-16 & 265 & 3842 & 4107 \\
\hline Jun-16 & 330 & 3900 & 4230 \\
\hline Jul-16 & 225 & 1972 & 2197 \\
\hline Agust-16 & 222 & 1897 & 2119 \\
\hline Sep-16 & 300 & 2500 & 2800 \\
\hline Okt-16 & 600 & 3750 & 4350 \\
\hline Nop-16 & 300 & 3224 & 3524 \\
\hline Des-16 & 250 & 3250 & 3500 \\
\hline $\begin{array}{c}\text { Total } 2 \\
\text { tahun } \\
\text { (24bulan) }\end{array}$ & 8029 & 66181 & 74210 \\
\hline
\end{tabular}
Tahun 2015 - 2016

Berdasarkan data diatas parameter serta hasil diskusi dan wawancara diperoleh informasi yang ada untuk masing-masing pembeli yaitu biaya pemesanan $\left(A_{b, j}\right)$, biaya penyimpanan $\left(\mathrm{h}_{\mathrm{b}, \mathrm{j}}\right)$, biaya kekurangan $\left(\mathrm{S}_{\mathrm{j}}\right)$, ratarata permintaan $\left(\mu_{\mathrm{j}}\right)$ dan standar deviasi permintaan $\left(\sigma_{\mathrm{j}}\right)$.

Sedang pada pemanufaktur biaya yang terlibat adalah biaya setup $\left(A_{v}=R p\right.$. $1.038 .600 /$ bulan), dan biaya simpan $\left(\mathrm{h}_{\mathrm{v}}=\mathrm{Rp}\right.$. $53.610 /$ unit/bulan). Setiap satu unit produk membutuhkan 5 item penyusun produknya (i= $1,2, . .5)$, untuk biaya pemesanan per item produknya adalah sama yaitu ( $\mathrm{a}_{\mathrm{vi}}=\mathrm{Rp} .178 .700$ ), sedang kebutuhan tiap-tiap item pembentuk produk $\left(\mathrm{u}_{\mathrm{i}}\right)$ dan biaya simpan item $\left(\mathrm{h}_{\mathrm{v}, \mathrm{i}}\right)$ 


\section{a. Solusi Hasil Tanpa Joint Economic Lot Size}

Langkah 1:

Dengan menggunakan rumus 1 , maka nilai $\mathrm{T}_{\mathrm{j}}^{*}$ masing-masing pembeli dapat dilihat dalam tabel 1. berikut:

Tabel. 2. Nilai T*j masing-masing pembeli

\begin{tabular}{|c|c|c|c|c|}
\hline \multirow{2}{*}{ Pembeli } & \multicolumn{2}{|c|}{$\mathrm{T}^{*}$ perhitungan } & \multicolumn{2}{c|}{$\mathrm{T}^{*}$ p penyesuaian } \\
\cline { 2 - 5 } & Bulan & Hari & Bulan & Hari \\
\hline 1 & 0,34 & 6,8 & 0,3 & 7 \\
\hline 2 & 0,099 & 1,84 & 0,09 & 2 \\
\hline
\end{tabular}

Langkah 2:
Selanjutnya nilai $\mathrm{Tj}^{*}$ digunakan untuk menghitung $\mathrm{I}_{\max }$, Safety Stock dan Ekspected shortage masing-masing pembeli. Nilai $\mathrm{I}_{\max }$

Tabel. 3. Nilai $I_{\max }$ safety stock, dan Expected shortage di masing-masing pembeli

\begin{tabular}{|c|c|c|}
\hline & \multicolumn{2}{|c|}{ Pembeli } \\
\hline & 1 & 2 \\
\hline$I_{\max }$ (unit) & 159 & 374 \\
\hline safety stock (unit) & 39 & 98 \\
\hline expected shortage & 0,362 & 0,612 \\
\hline
\end{tabular}

\section{Langkah 3:}

Untuk mencari besarnya pesanan pembeli tiap siklusnya (QTI), terlebih dahulu dicari nilai akhir persediaan (ITI) masing-masing pembeli. Setelah itu besarnya pesanan pembeli tiap siklusnya (QTI), dimana QTI = Imax - ITI

Tabel. 4. $\mathrm{I}_{\mathrm{Tl}}$ dan $\mathrm{Q}_{\mathrm{Tl}}$ masing-masing pembeli

\begin{tabular}{|c|c|c|c|c|c|c|c|c|c|c|c|c|}
\hline \multicolumn{13}{|c|}{ Siklus pemesanaan (hari) } \\
\hline & Pembeli & 0 & 7 & 14 & 21 & & & & & & & \\
\hline \multirow{4}{*}{1} & Iti (unit) & 0 & 139 & 134 & 141 & & & & & & & \\
\hline & Qti (unit) & 0 & 20 & 25 & 18 & & & & & & & \\
\hline & Imax (unit) & 159 & 159 & 159 & 159 & & & & & & & \\
\hline & Demand (unit) & 20 & 25 & 18 & 15 & & & & & & & \\
\hline \multirow{5}{*}{2} & Pembeli & $\mathbf{0}$ & 2 & 4 & 6 & 8 & 10 & 12 & 14 & 16 & 18 & 20 \\
\hline & Iti (unit) & 0 & 251 & 226 & 224 & 214 & 294 & 255 & 271 & 237 & 196 & 201 \\
\hline & Qti (unit) & 0 & 123 & 148 & 150 & 160 & 80 & 119 & 103 & 237 & 178 & 173 \\
\hline & Imax (unit) & 374 & 374 & 374 & 374 & 374 & 374 & 374 & 374 & 374 & 374 & 374 \\
\hline & Demand (unit) & 123 & 148 & 150 & 160 & 80 & 119 & 103 & 137 & 178 & 173 & 85 \\
\hline
\end{tabular}

Total biaya di pembeli 1 Rp. 15.820 .000 dan pembeli 2 Rp. 33.320.000.

Langkah 4:

Untuk nilai $\mathrm{T}^{*} \mathrm{j}$, Imax, dan ekspected shortage yang tetap nilai $\lambda^{*} \mathrm{v}$,j dicari dengan menggunakan rumus 2 . untuk nilai yang paling minimum.

Tabel. 5. Nilai pengiriman dan total biaya pemanufaktur untuk masing-masing pembeli.

\begin{tabular}{|c|c|c|}
\hline \multirow{2}{*}{$\operatorname{Tcv} \lambda_{v, j}$} & \multicolumn{2}{|c|}{ (Rupiah) } \\
\hline & 1 & 2 \\
\hline 1 & $5.520 .000,00$ & $19.320 .000,00$ \\
\hline 2 & $5.332 .000,00$ & $33.210 .000,00$ \\
\hline 3 & $6.984 .000,00$ & $53.550 .000,00$ \\
\hline 4 & - & $75.490 .000,00$ \\
\hline 5 & - & $98.070 .000,00$ \\
\hline 6 & - & $121.000 .000,00$ \\
\hline 7 & - & $144.100 .000,00$ \\
\hline 8 & - & $167.300 .000,00$ \\
\hline 9 & - & $190.600 .000,00$ \\
\hline 10 & - & $213.900 .000,00$ \\
\hline Optimal & Rp 5.332.000,00 & Rp $19.320 .000,00$ \\
\hline
\end{tabular}

Langkah 5:

Dari tabel diatas terlihat bahwa nilai $\lambda v, \mathrm{j}$ optimal masing masing pembeli berbeda, untuk pembeli 1 nilai $\lambda^{*} \mathrm{v}$,j pada saat bernilai 2 dengan biaya Rp.5.322.000, pembeli 2 pada saat bernilai 1 dengan biaya Rp.19.320.000.

Langkah 6:

Total biaya rantai pasok berasal dari penjumlahan biaya-biaya pada pembeli dan biaya di pemanufaktur. Total biaya minimumnya sama dengan Rp. 73.790.000,00.

\section{b. Solusi Hasil Dengan Joint Economic Lot Size}

Pencarian solusi terhadap nilai $\mathrm{T}^{*}$ dan $\lambda^{*}$ yang dapat meminimumkan total biaya rantai pasok yang dapat dilakukan dengan menggunakan satu algoritma. 


\section{Langkah 1:}

Ditetapkan $\lambda=1$ dan didapatkan nilai siklus pemesanan optimal $\left(\mathrm{T}^{*}\right)=0,203$ bulan atau 4 hari yang berasal dari TCJels $(\mathrm{T}, \lambda)$ yang paling kecil. Nilai TCJels $(T, \lambda)$ dan $T^{*}$.

Tabel. 6. Waktu siklus dan Total Biaya Rantai

\begin{tabular}{|c|r|}
\multicolumn{2}{|c|}{ Pasok } \\
\hline $\boldsymbol{\Lambda}$ & $\mathbf{T C}_{\text {chain }}(\mathbf{T}, \boldsymbol{\lambda}) \mathbf{( R p )}$ \\
\hline 0,203 & $\mathrm{Rp}$ \\
& $68.370 .000,00$ \\
\hline 0,204 & $\mathrm{Rp}$ \\
0,205 & $68.430 .000,00$ \\
\hline & $\mathrm{Rp}$ \\
0,206 & $68.500 .000,00$ \\
\hline & $\mathrm{Rp}$ \\
0,207 & $68.560 .000,00$ \\
\hline $\mathrm{Rp}$ \\
\hline
\end{tabular}

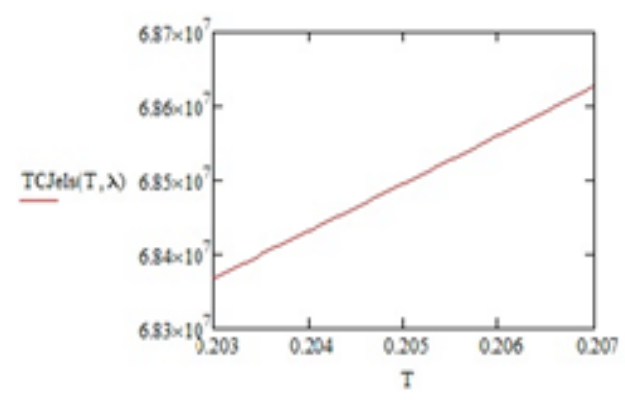

Gambar. 1. Grafik perbandingan total biaya rantai pasok dengan waktu siklus

Berdasarkan tabel 6. Dan gamabar 1. terlihat bahwa nilai TCJels(T, $\lambda$ ) terkecil terjadi pada saat $\mathrm{T}=0,203$ bulan atau 4 hari.

\section{Langkah 2:}

Nilai $\mathrm{T}^{*}$ digunakan untuk menghitung Imax, Safety Stock dan ekspected shortage masing-masing pembeli.

Tabel. 7. Nilai $I_{\max }$ safety stock, dan expected shortage di masing-masing pembeli

\begin{tabular}{|c|c|c|}
\cline { 2 - 3 } \multicolumn{1}{c|}{} & \multicolumn{2}{c|}{ Pembeli } \\
\cline { 2 - 3 } \multicolumn{1}{c|}{} & $\mathbf{1}$ & $\mathbf{2}$ \\
\hline $\mathbf{I}_{\max }$ & 98 & 690 \\
\hline $\begin{array}{c}\text { Safety } \\
\text { Stock }\end{array}$ & 30 & 138 \\
\hline $\begin{array}{c}\text { Expected } \\
\text { Shortage }\end{array}$ & 0,017 & 0,02 \\
\hline
\end{tabular}

Nilai Imax untuk pembeli 1, 2 setiap siklusnya masing-masing adalah 98 unit dan 690 unit.

\section{Langkah 3:}

Besarnya pesanan pembeli tiap siklusnya (QTI) dan nilai akhir persediaan (ITI).
Tabel. 8. ITl dan QTl masing-masing pembeli Siklus pemesanaan (hari)

\begin{tabular}{|c|l|c|c|c|c|c|c|}
\hline $\begin{array}{c}\text { Pembel } \\
\text { i }\end{array}$ & & $\mathbf{0}$ & $\mathbf{4}$ & $\mathbf{8}$ & $\mathbf{1 2}$ & $\mathbf{1 6}$ & $\mathbf{2 0}$ \\
\hline 1 & $\begin{array}{l}\text { Iti } \\
\text { (unit) }\end{array}$ & 0 & 48 & 73 & 53 & 48 & 26 \\
\hline & $\begin{array}{l}\text { Qti } \\
\text { (unit) }\end{array}$ & 0 & 50 & 25 & 45 & 50 & 72 \\
\hline & $\begin{array}{l}\text { Imax } \\
\text { (unit) }\end{array}$ & 98 & 98 & 98 & 98 & 98 & 98 \\
\hline & $\begin{array}{l}\text { Deman } \\
\text { d (unit) }\end{array}$ & 50 & 25 & 45 & 50 & 72 & 50 \\
\hline $\begin{array}{c}\text { Pembel } \\
\text { i }\end{array}$ & $\begin{array}{l}\text { Iti } \\
\text { (unit) }\end{array}$ & 0 & 340 & 290 & 490 & 215 & 40 \\
\hline & $\begin{array}{l}\text { Qti } \\
\text { (unit) }\end{array}$ & 0 & 350 & 400 & 200 & 475 & 650 \\
\hline & $\begin{array}{l}\text { Imax } \\
\text { (unit) }\end{array}$ & 690 & 690 & 690 & 690 & 690 & 690 \\
\hline & $\begin{array}{l}\text { Deman } \\
\text { d (unit) }\end{array}$ & 350 & 400 & 200 & 475 & 650 & 119 \\
\hline
\end{tabular}

Siklus pemesanan pembeli 1 dan pembeli 2 adalah sama pada setiap 0,203 bulan atau 4 hari, sedangkan nilai sisa persediaan (ITl) dan jumlah pemesanannya (QTI) setiap akhir siklus selama 4 siklus.

Total biaya di pembeli 1 Rp. 15.290.000,00 dan pembeli 2 Rp. 43.230.000,00

\section{Langkah 4:}

Untuk nilai $\mathrm{T}^{*}$, Imax, dan ekspected shortage yang tetap dan nilai $\lambda$ yang berbedabeda $(\lambda=1,2, \ldots, 5)$ didapatkan hasil total biaya rantai pasok (TCJels(T, $\lambda)$ ).

Tabel. 9. Nilai $\lambda$ dan TCjels $(\mathrm{T}, \lambda)$ untuk nilai $\mathrm{T}^{*}=0,203$ Bulan

\begin{tabular}{|l|rr|}
\hline $\boldsymbol{\lambda}$ & \multicolumn{2}{|c|}{ TCJels $(\mathbf{T}, \boldsymbol{\lambda})$} \\
\hline $\mathbf{1}$ & $\mathrm{Rp}$ & $68.370 .000,00$ \\
\hline $\mathbf{2}$ & $\mathrm{Rp}$ & $112.500 .000,00$ \\
\hline $\mathbf{3}$ & $\mathrm{Rp}$ & $159.800 .000,00$ \\
\hline $\mathbf{4}$ & $\mathrm{Rp}$ & $207.800 .000,00$ \\
\hline $\mathbf{5}$ & $\mathrm{Rp}$ & $256.200 .000,00$ \\
\hline
\end{tabular}

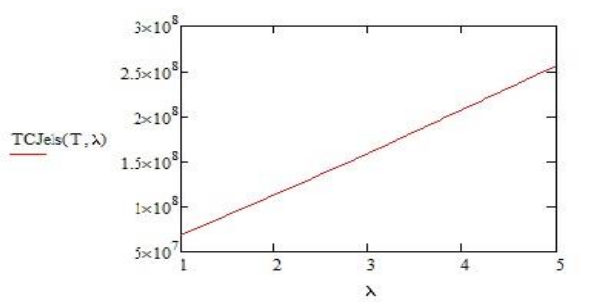

Gambar 2. Grafik perbandingan total biaya rantai pasok dengan waktu siklus 
Berdasarkan tabel 9. dan gambar 2. diatas terlihat bahwa nilai TCJels $(\mathrm{T}, \lambda)$ yang terkecil terjadi jika pengiriman dari pemanufaktur ke setiap pembeli dilakukan 1 kali pengiriman.

\section{Langkah 5:}

Nilai TCJels (T, $\lambda$ ) yang terkecil (tabel 9) terjadi pada saat nilai $\mathrm{T}^{*}=0,203$ bulan dan $\lambda^{*}=$ 1 , atau bisa dituliskan bahwa nilai TCJels ( $\mathrm{T}^{*}$, $\left.\lambda^{*}\right)=$ Rp.68.370.000,00 adalah total biaya rantai pasok yang minimum.
Berdasarkan

langkah-langkah penyelesaian masalah tersebut didapatkan hasil bahwa pemesanan untuk semua pembeli mengikuti siklus pemesanan ( $\mathrm{T}^{*}$ ) setiap 0,203 bulan atau 4 hari dan pemanufaktur melakukan pengiriman satu kali $\left(\lambda^{*}=1\right)$ ke masing-masing pembeli setiap siklusnya, yang menghasilkan total biaya rantai pasok antara pemanufaktur dengan kedua pembeli yang minimum TCJels $\left(\mathrm{T}^{*}, \lambda^{*}\right)=$ Rp. 68.370.000,00.

\section{c. Perbandingan Antara Tanpa Penerapan Joint Economic Lot Size dan dengan Penerapan Joint Economic Lot Size}

Tabel. 10. Nilai $\mathrm{T}_{\mathrm{j}}^{*}, \lambda_{\mathrm{j}}^{*}, \mathrm{I}_{\max }, \mathrm{C}_{\mathrm{B}}, \mathrm{cv}$, dan $\mathrm{TC}_{\text {chain }}$ jika Joint Economic Lot Size tidak dilaksanakan

\begin{tabular}{|c|c|c|c|c|c|}
\hline \multirow{2}{*}{ Pembeli } & \multicolumn{5}{|c|}{ Tanpa JELS } \\
\hline & $\mathrm{T}^{*}{ }_{\mathrm{j}}(/$ tahun $)$ & $\lambda_{\mathrm{j}}^{*}$ & $\begin{array}{c}I_{\max } \\
\text { (unit) }\end{array}$ & $\mathrm{C}_{\mathrm{B}}(\mathrm{Rp})$ & $\mathrm{C}_{\mathrm{V}}(\mathrm{Rp})$ \\
\hline 1 & 0,34 & 7 & 159 & 15.820 .000 & 5.332 .000 \\
\hline 2 & 0,099 & 2 & 374 & 33.320 .000 & 19.320 .000 \\
\hline $\mathrm{TC}\left(\mathrm{T}^{*}, \lambda^{*}\right)(\mathrm{Rp})$ & \multicolumn{5}{|c|}{73.790 .000} \\
\hline
\end{tabular}

Dari tabel diatas dapat dilihat bahwa masing-masing pembeli menentukan sendiri siklus pemesanannya dengan tujuan untuk meminimalkan total biaya yang terjadi pada masing-masing pembeli.

Tabel. 11. Nilai $\mathrm{T}_{\mathrm{j}}^{*}, \lambda_{\mathrm{j}}^{*}, \mathrm{I}_{\max }, \mathrm{C}_{\mathrm{B}}, \mathrm{cv}$, dan $\mathrm{TC}_{\text {chain }} \mathrm{jika}$ Joint Economic Lot Size dilaksanakan

\begin{tabular}{|c|c|c|c|c|c|}
\hline \multirow[b]{2}{*}{ Pembeli } & \multicolumn{5}{|c|}{ Dengan JELS } \\
\hline & $\mathrm{T}^{*}(/$ tahun $)$ & $\lambda^{*}$ & $\begin{array}{c}I_{\max } \\
\text { (unit) }\end{array}$ & $\mathrm{C}_{\mathrm{B}}(\mathrm{Rp})$ & $\mathrm{C}_{\mathrm{V}}(\mathrm{Rp})$ \\
\hline 1 & 0,203 & 4 & 98 & 15.290 .000 & \multirow{2}{*}{9.661 .000} \\
\hline 2 & 0,203 & 4 & 690 & 43.230 .000 & \\
\hline $\mathrm{TC}_{\text {jels }}\left(\mathrm{T}^{*}, \lambda^{*}\right)(\mathrm{Rp})$ & \multicolumn{5}{|c|}{68.370 .000} \\
\hline
\end{tabular}

Diatas terlihat bahwa terjadi penghematan total biaya rantai pasok, penghematan yang terjadi sebesar Rp. 73.790 .000 - Rp.68.370.000 = Rp. 5.420.000.

\section{PENUTUP}

Dari hasil analisa data maka dapat dijabarkan hasil kesimpulan penelitian di PT. MPX adalah sebagai berikut :Rentang waktu yang optimal pada saat sebelum menerapkan JELS pada pembeli 1 dan 2 berbeda-beda yaitu melakukan pemesanan setiap 7 hari dan 2 hari dengan jumlah 19 unit dan 174 unit. Sedangkan setelah menerapkan JELS rentang waktu yang optimal adalah 4 hari dengan jumlah pemesanan 361 unit, Total biaya sebelum menerapkan JELS adalah Rp. 15.820 .00 dan Rp. 33.320.000. sedangkan setelah menerapkan JELS total biaya berubah menjadi Rp. 530.000 dan Rp. 9.910.000.

\section{DAFTAR PUSTAKA}

Anshori, Moch, I Nyoman Pujawan, and Stevanus Eko Wiratno. 2017. "Model Koordinasi Pemanufaktur Tunggal Multi Pembeli Dengan Permintaan Probabilistik."

Goyal, S K. 1977. “An Integrated InventoryModel for a Single Supplier-Single Customer Problem." The International Journal of Production Research 15(1): 107-11.

Prawirosentono, Suyadi. 2001. "Manajemen Operasi Edisi Ketiga.” Jakarta: PT. Bumi Aksara. 
D. Santiningtyas,dkk /JISO, Vol. 1, No.1, Desember 2018, 23-28

Halaman ini sengaja dikosongkan 